FULL RESEARCH ARTICLE

\title{
Population ecology and survivorship of San Joaquin antelope squirrels in grazed and control plots in the San Joaquin Desert of California
}

\author{
DAVID J. GERMANO ${ }^{1 *}$, LAWRENCE R. SASLAW ${ }^{2}$, GALEN B. RATHBUN†ํ․ AND \\ BRIAN L. CYPHER ${ }^{2}$
}

${ }^{1}$ Department of Biology, California State University, Bakersfield, CA 93311, USA

${ }^{2}$ Endangered Species Recovery Program, California State University-Stanislaus, One University Circle, Turlock, CA 95382, USA

${ }^{3}$ Institute of Biodiversity Science and Sustainability, California Academy of Sciences, San Francisco, CA 94118, USA

* Corresponding Author: dgermano@csub.edu

tDeceased

The San Joaquin antelope squirrel (Ammospermophilus nelsoni) is endemic to the San Joaquin Desert of California. It has been listed as Threatened by the state of California since 1980 due to profound habitat loss, but a paucity of information could limit conservation efforts for this species. We examined data collected each August during 1997-2006 to determine whether $A$. nelsoni population attributes differed between grazed and ungrazed study plots. We found that sex ratios, mean weights, percentage of reproductive males, number of young, yearly survival, longevity, overall survivorship, and population growth trajectories all were similar between grazed and ungrazed plots. In general, sex ratios were even, males were heavier than females, some males were reproductive in August (although most females were not), and the number of young was inversely related to residual dry matter. We also found that we captured most individuals only once, but we captured a few squirrels for up to for 5 years, and the populations on both grazed and ungrazed plots were growing during the 10-year study. Our study was only the second long-term investigation of this species and the information is needed for further conservation and recovery efforts.

Key words: Ammospermophilus nelsoni, conservation, reproduction, sex ratios, survival, sex ratios 
The San Joaquin antelope squirrel (Ammospermophilus nelsoni; Fig. 1) is a small ground squirrel endemic to the San Joaquin Desert in central California (Best et al. 1990c; USFWS 1998; Germano et al. 2011). This species once was widely distributed in arid shrubland and grassland habitats throughout this region; however, extensive conversion of these habitats to agricultural, urban, and industrial uses has imperiled this species along with a suite of other co-occurring endemic species. Consequently, A. nelsoni was state listed as Threatened in 1980 (USFWS 1998).

Despite being a species of conservation concern, relatively few ecological investigations have been conducted on this species. Data on life-history attributes, distribution, and habitat relationships have been published by Grinnell and Dixon (1918), Hawbecker (1947, 1953, 1958, 1959), Otten and Cypher (1999), Cypher (2001), Harris (2019), and Germano et al. (2021). More germane to the conservation of A. nelsoni, Germano et al. (2012) assessed the effects of grazing on population trends of this species while Fiehler et al. (2017) assessed the effects of oil field activities. Additional information, particularly on factors affecting population dynamics, however, is necessary for conserving A. nelsoni.

From 1997-2006, we collected data on a suite of vertebrates, including $A$. nelsoni, on a site in the San Joaquin Desert to assess the effects of grazing on these species (Germano et al. 2012). Abundance trends for $A$. nelsoni were assessed on grazed and control plots. We found that numbers of $A$. nelsoni were much greater on grazed plots than control plots when the area warranted grazing and numbers were inversely correlated with amounts of herbaceous plant growth. Here, we further analyze these data to assess demographic attributes of $A$. nelsoni. Our objectives were to determine whether demographic attributes varied with respect to grazing, and whether attributes varied over time with fluctuations in annual environmental conditions.

\section{METHODS}

\section{Study Area}

We studied $A$. nelsoni in a region commonly referred to as the Lokern Natural Area (Fig. 2), which is in the southwestern end of the San Joaquin Desert (Germano et al. 2011), about $50 \mathrm{~km}$ west of Bakersfield in Kern County, California. The site (35'22'24'N 119 36'33'”W, $158 \mathrm{~m}$ elevation) is a large area of relatively undisturbed habitat situated on a broad alluvial fan at the base of the Elk Hills. The natural area is situated between intensive agriculture to the east and north and oil fields to the west and south. The site is dominated by saltbush (Atriplex spp.), non-native annual grasses, and native annual forbs (Germano et al. 2012). Because the natural area is large (5,285 ha), relatively undisturbed, and mostly protected, other ecological studies have been performed there (Cypher et al. 2009; Germano et al. 2012; Germano and Rathbun 2016).

\section{Data Collection}

We caught $A$. nelsoni on grazed treatment plots and ungrazed control plots, with four replicates. Each treatment plot $\left(2.6 \mathrm{~km}^{2}\right.$ or $\left.1 \mathrm{mi}^{2}\right)$ was defined by section boundaries (Sections 21, 27, 29, and 33 of Township 29 South, Range 22 East). The treatments were adjacent to each other in a four-leaf clover pattern, with a fifth section enclosed in the middle $(35.3762 \mathrm{~N}, 119.61614 \mathrm{~W})$, which served as a pasture to temporarily place livestock while moving them into or out of the 4 surrounding treatment pastures (Fig. 3). The 4 control 


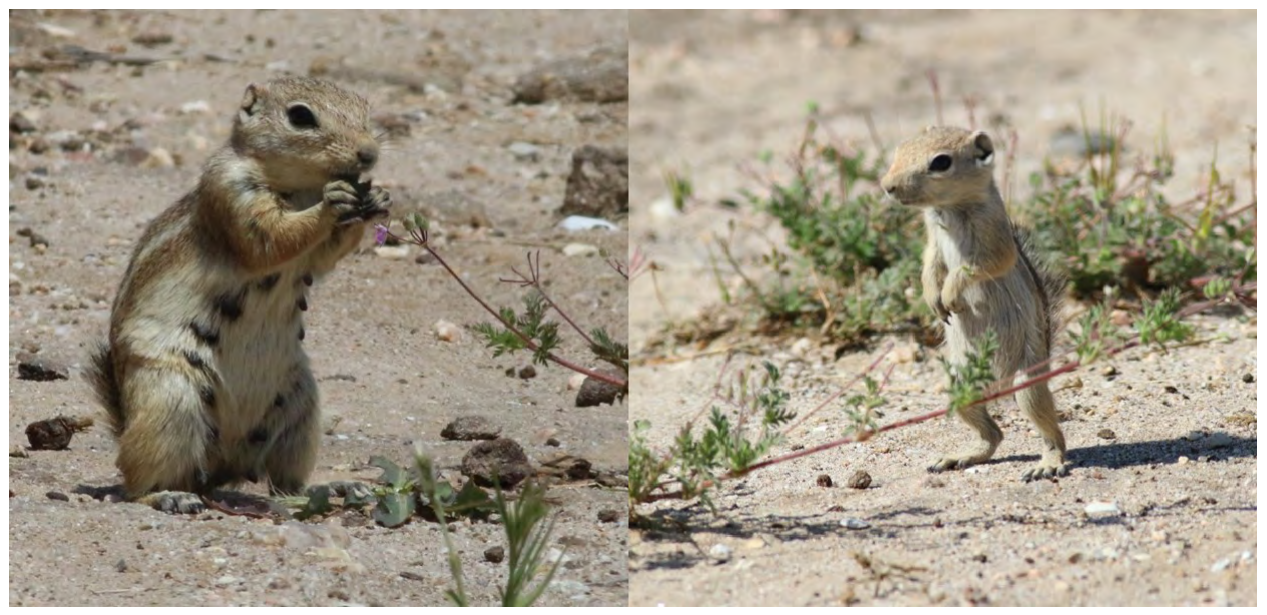

Figure 1. Adult female (left) and juvenile (right) San Joaquin antelope squirrel (Ammospermophilus nelsoni) photographed 23 April 20173.2 km south of Tupman, Kern County, California. (Photo Credit: Larry Saslaw).

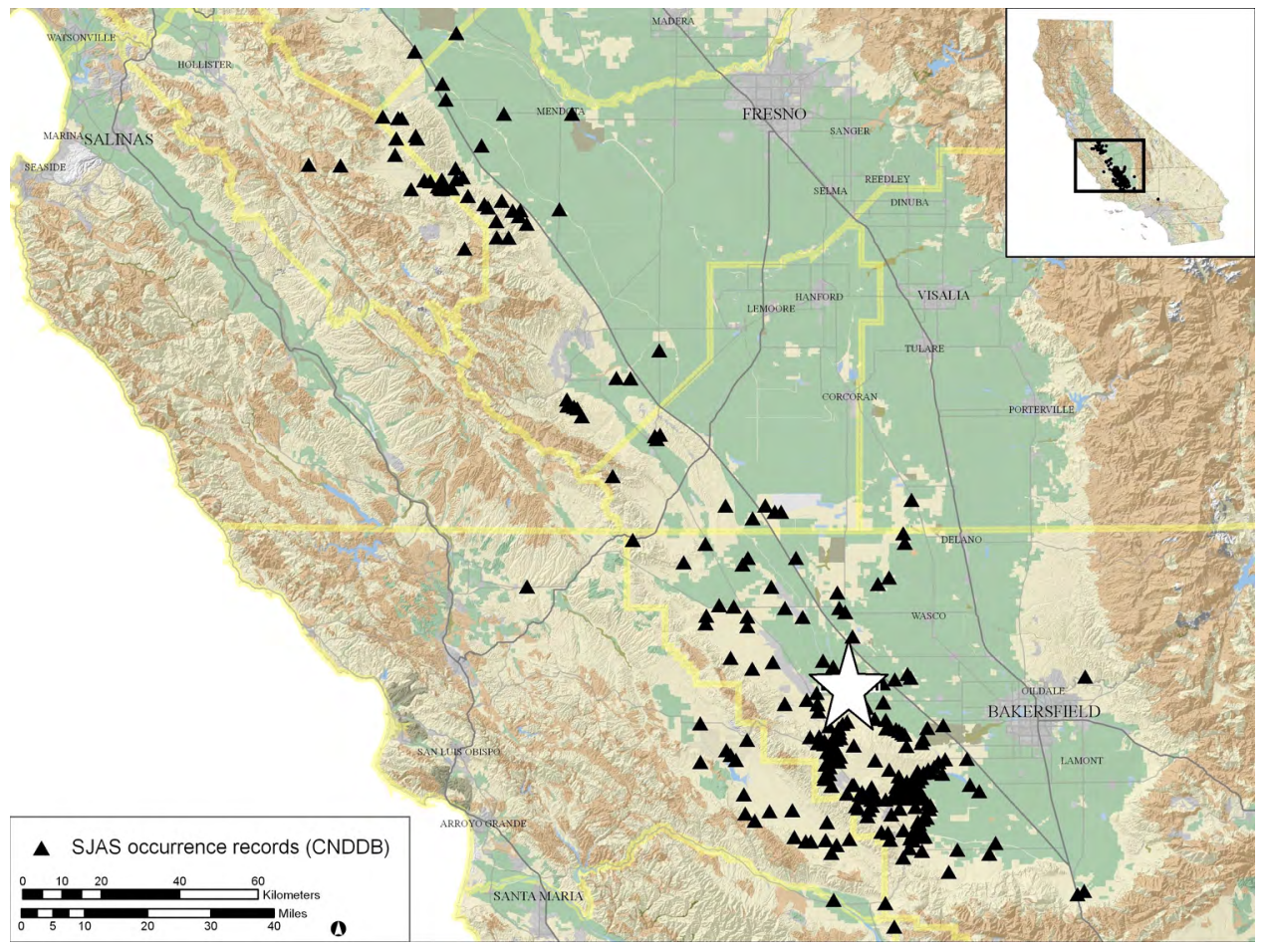

Figure 2. Occurrence records (black triangles) of the San Joaquin antelope squirrel (Ammospermophilus nelsoni) in the San Joaquin Desert of California. The approximate location of the Lokern Study Site (white star) is where we conducted a 10 -year study of antelope squirrels. 
pastures were 25 ha (62 acres) each, and each square exclosure was located within a corner of a treatment pasture to reduce fencing costs (Fig. 3). Although control plots were within a smaller surrounding area than treatment plots, previous experience with the movements of squirrels indicated that the plot sizes were not likely to be a factor with our design, and this was confirmed based on sizes of home ranges of squirrels (Germano et al. 2021) and our extensive mark-recapture data associated with this project. Of the 1,265 individual squirrels we caught in 10 years of trapping, only 3 individuals switched between control and treatments plots, and 2 returned to their original plot.

We developed a cooperative agreement with the landowner (Chevron Production Company) and a local cattle operator (Eureka Livestock Company) to provide cattle graz-

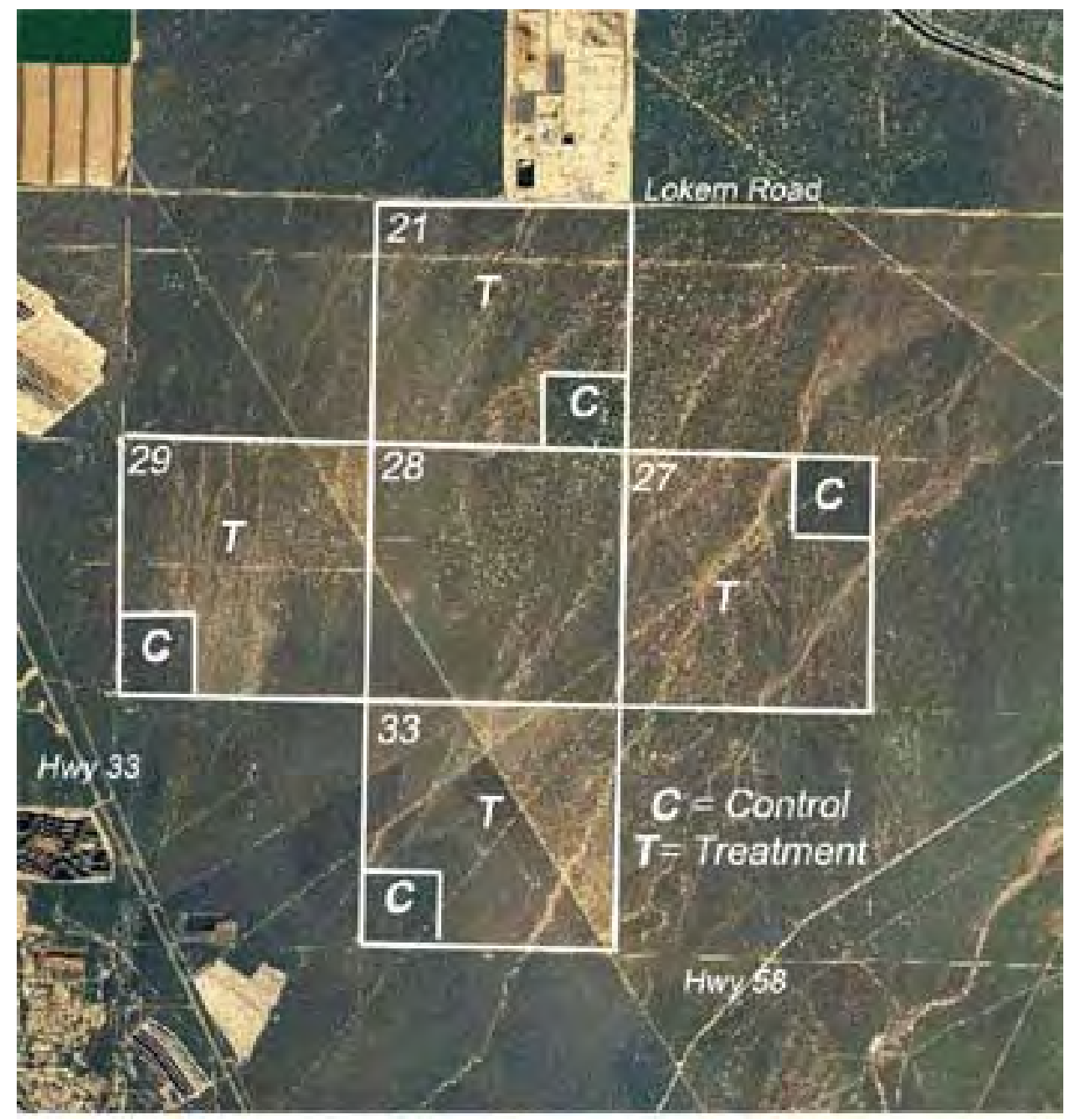

Figure 3. Experimental design of the livestock grazing study in the Lokern Natural Area in western Kern County (T29S, R22E), California, where San Joaquin antelope squirrels (Ammospermophilus nelsoni) were trapped yearly on 4 grazed (T) and 4 control plots (C), 1997-2006. Each large block is $1 \mathrm{mi}^{2}$ and numbers are section numbers. 
ing on the treatment plots. The stocking rate and timing of grazing was determined by our objective of maintaining about $560 \mathrm{~kg}$ of herbaceous vegetation per ha (500 lb per acre) at the end of the winter growing season. We aimed to start grazing by 1 December each year but would not turn out cattle unless there was at least $784 \mathrm{~kg}$ per ha (700 pounds per acre) residual dry matter or $5 \mathrm{~cm} \mathrm{(2} \mathrm{in)} \mathrm{of} \mathrm{new} \mathrm{green} \mathrm{growth.} \mathrm{If} \mathrm{grass} \mathrm{growth} \mathrm{did} \mathrm{not} \mathrm{attain} \mathrm{the}$ minimum standard in any year, then pastures were not grazed that year. Our objective was to attain the minimum dry mulch amount (or residual dry matter; RDM) by at least 1 April each year when the livestock were removed. During the 10-year study, rainfall varied from a high of $412.5 \mathrm{~mm}$ in the winter of 1997-1998 to a low of 80.5 mm in 2001-2002 (Fig. 4). Cattle were turned out onto the newly fenced treatment plots for the first time in February 1998. The yearly plot, vegetation, and animal sampling schemes were completed as planned in 1998, and the cattle were removed in July 1998, just prior to mammal trapping. In 1999, 2000, and 2001, a similar schedule was followed, although with progressively lower grazing intensity as conditions dried each successive year. Because rainfall was well below average and minimum forage was not available, cattle were not on the plots from 2002-2004. In 2005, rainfall was above average and was about average in 2006, so cattle

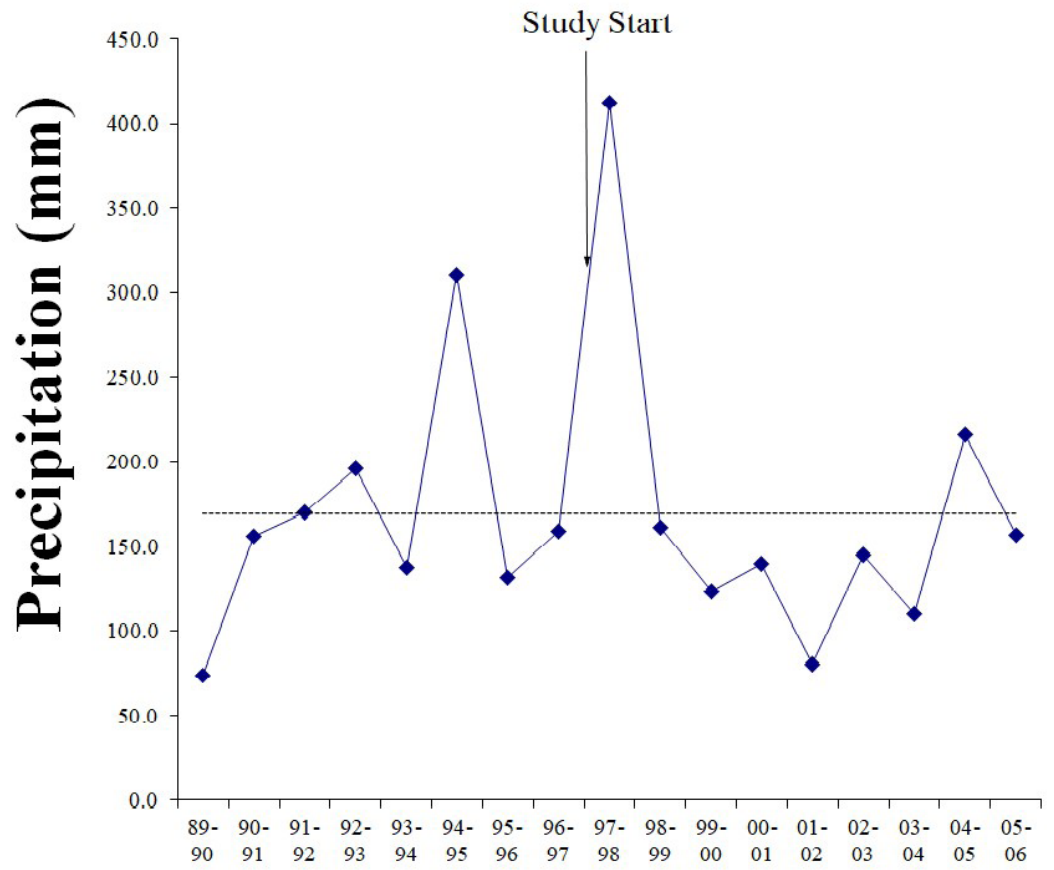

Rainfall Year

Figure 4. Rainfall in the Lokern area from 1989 to 2006. Data are from the Buena Vista Water District in Buttonwillow, California, about $11 \mathrm{~km}$ northeast of the study site. The dotted line is the Buttonwillow 20-year mean of $169 \mathrm{~mm}$. 
grazed the treatment plots for a brief period in both years. The duration of our study had to be long enough to encompass variation from several environmental factors, including the wild fire in 1997, the El Niño winter of 1997-1998, initial low populations of terrestrial vertebrates (Germano et al. 2012), and year-to-year variation in rainfall and numerous other environmental factors that are typical of a desert.

We established permanent $8 \times 8$ live-trapping grids on each study plot consisting of 64 traps at 40-m intervals. This grid was superimposed on a transect grid set up for sampling lizards (Germano et al. 2012). We baited the traps with rolled oats and opened and checked the traps during 6 consecutive mornings once a year, between the end of July and the first of September. We monitored 4 grids at once, either 4 treatment plots or 4 controls, waited 1-2 weeks, and then trapped at the other 4 grids. Thus, the yearly trapping of treatment and control grids took 3-4 weeks.

We used collapsible single-door live traps (Model 13, Tomahawk Trap Co., Tomahawk, WI, USA), which were opened at dawn and closed at noon, or when ambient air temperature exceeded $35^{\circ} \mathrm{C}\left(95^{\circ} \mathrm{F}\right)$, whichever occurred first. We shaded each trap from the sun with burlap. While open, we checked the traps every 2 hours. For each squirrel captured, we recorded the trap location on the grid, its sex and weight, and we applied a unique mark on the fur with a black felt-tip pen (Sharpie Permanent Marker). We also tagged each squirrel with a passive integrated transponder (PIT) tag (Model TX1400 series, Biomark, Boise, ID, USA) inserted subcutaneously on the back with a hypodermic needle (Schooley et al. 1993).

\section{RDM and Invertebrate Numbers}

We measured the RDM on each trapping grid in which we caught squirrels (Germano et al. 2012). This was done in August during trapping sessions using 30 quarter- $\mathrm{m}^{2}$ $(50 \times 50 \mathrm{~cm})$ quadrats placed randomly in the trapping grid. This gave us a measure of the herbaceous plant production for the year. We also checked 10 pitfall traps arrayed along the edge of each plot each day during trapping (Germano et al. 2012). Pit-fall traps were 19.1 L plastic buckets that we had dug into the ground up to the edge of the bucket. Traps were open continuously during the 6 days of squirrel trapping. We averaged the number of invertebrates found in the traps as an estimate of arthropod abundance on each plot for $A$. nelsoni. We excluded the number of ants we found in invertebrate numbers as they are not typically food for A. nelsoni (Hawbecker 1947) and ant numbers were much higher than other invertebrates (Germano et al. 2012), which we suspected would skew our comparisons.

\section{Data Analyses}

We estimated sex ratios, mean adult weights, percentage of adults reproductive, and the number of young on control and grazed plots. To determine if there were significant differences in these life-history traits between control and grazed plots, we used General Linear Models (GLM) models. For sex ratios, we compared numbers of males and females by year, sex, and treatment with an interaction of year $\times$ sex $\times$ treatment.

We compared adult weights using year, sex, and treatment as main effects, RDM and number of invertebrates as covariates, and the interactions year $\times$ treatment, year $\times$ sex, treatment $\times$ sex, and year $\times$ sex $\times$ treatment. We determined adults to be any squirrel caught for the first time with a weight $>110 \mathrm{~g}$. Based on recent trapping we have done (2019-2020), it is possible that some of these individuals might have been young of the year born in 
February or March, but a few squirrels that weighed 109-118 g in later years of trapping in this study had been caught the previous year. We did not include data for 1999 because there was only one datum for females on the control plots. All other groups for other years had a sample size of at least 4 (most $>15)$.

We judged male squirrels to be reproductive if they were scrotal (testicles fully descended). We found many males that we judged to be partially scrotal, but we could not be certain that testicles were descending or if they were regressing. For females, we determined an individual to be reproductive if she was pregnant (abdomen distended and high weight), lactating (enlarged nipples), or in estrous (swollen vagina). For comparing the percentage of adults that were reproductive on control and grazed plots, we could only test main effects of year and treatment because only two females (of hundreds of captures) showed any indication of being reproductive. Therefore, we only tested males.

We compared the number of young ( $\leq 110 \mathrm{~g}$ at first capture) found on a plot by year and treatment with RDM as a covariate. Because of a low number of degrees of freedom, we could not include an interaction term. We also used a Pearson's Product Moment Correlation of the number of young to RDM using the number of young on control (combined) and grazed (combined) plots each year as separate points $(\mathrm{n}=18)$.

We estimated year to year survival on control and grazed plots by determining the number of individuals marked in one year that were caught in the next year or subsequent years. To determine if there were significant differences in 2 year survival of squirrels between control and grazed plots, we used a GLM model with year, sex, and treatment as main effects, RDM and the number of invertebrates as covariates, and an interaction of year $\times$ sex $\times$ treatment. We estimated longevity of male and female squirrels from recaptures across sessions. The number of sessions across which we found a given individuals was used as the minimum longevity for the individual. For example, if we captured an individual in 2 consecutive years, then not in the next year, but again the following year, we estimated that this squirrel was at least 4 years old when we last caught it (adults when first captured were at least $1 \mathrm{y}$ old). For all tests above, $\alpha=0.05$.

Survivorship.-We calculated recapture and demographic vital rates of A. nelsoni using population encounter histories derived from individual encounter histories in Program MARK (White and Burnham 1999). We calculated population size (N), apparent survival $(\Phi)$, and recapture rates $(p)$ using open population Cormack-Jolly-Seber (CJS) and POPAN models in Program MARK (Lebreton et al. 1992; White and Burnham 1999). We generated CJS model sets for both control and grazed plots based on group designation (female and male) to test whether $\Phi$ or $p$ was best estimated independent of group or time, by group or time, or with a group $\times$ time interaction (generating 16 models). Model selection was based on Akaike Information Criterion ( $\mathrm{AIC}_{\mathrm{c}}$ ) values, with lower values denoting greater parsimony (Burnham and Anderson 2002) and we included $\Delta \mathrm{AIC}_{\mathrm{c}}$ (difference between model $\mathrm{AIC}_{\mathrm{c}}$ and lowest $\mathrm{AIC}_{\mathrm{c}}$ in the model set), $\omega$ (Akaike model weight), $k$ (number of estimable parameters), and Deviance (measure of model fit). Apparent survival and recapture rates were based on model averaging.

Traditionally, encounter rates are used to calculate the probability that an individual will leave a population. If the encounter rates are reversed, then the probability of an individual entering the population can be estimated (Pradel 1996) where: Lambda $(\lambda)=$ rate of individuals entering a population or cohort. Using Pradel models, $\lambda$ estimates the realized growth rates of the age class from which the encounter rates were generated but is not necessarily equivalent to the growth rate of the population. Still, it provides an important metric of the 
life-history characteristics of a population. Pradel's $\lambda$ was estimated by Program MARK in conjunction with the CJS-model described above.

\section{RESULTS}

From 1997 to 2006, the sex ratios of $A$. nelsoni on the Lokern varied from 0.79M:1.00F to $1.53 \mathrm{M}: 1.00 \mathrm{~F}$, but these differences were not significantly different than $1 \mathrm{M} / 1 \mathrm{~F}$ (Table 1 ). There was a significant interaction of year, treatment, and sex on adult weights (Table 1), with males have significantly higher weights in most years in grazed and control plots, but no difference in 2002 on either plot type, and females heavier than males in 2000 and 2006 on control plots and heavier in 2004 on grazed plots (Fig. 5). Irrespective of year or treatment type, adult males averaged $136.2 \mathrm{~g} \mathrm{(} \pm 0.680$ standard error [SE]; range, 111-196 g) and adult females averaged $126.5 \mathrm{~g}( \pm 0.568 \mathrm{SE}$; range, $111-163 \mathrm{~g})$. If most squirrels weighing $111-119 \mathrm{~g}$ are actually subadults ( $>95 \%$ in this weight range were first captures) and we designate adults as those weighing $\geq 120 \mathrm{~g}$, then adult males averaged $140.6 \mathrm{~g}( \pm 0.642$ $\mathrm{SE}$; range, $120-196 \mathrm{~g}$ ) and adult females averaged $130.9 \mathrm{~g} \mathrm{(} \pm 0.566 \mathrm{SE}$; range, 120-163 g).

Of the 345 captures we made of adult females over the 10 summers of our study, we only found two females that we categorized as reproductive. In 1998 on a control plot, one female was lactating, and in 2002 on a grazed plot, one female was in estrous. In contrast, $16.1 \%$ of the 528 captures of males were scrotal (range, $0-66.7 \%$; Table 2 ). The percentage of males that were reproductive differed significantly by year, but not by treatment type (Table 1). The number of young we caught on plots in the summer varied from one to 36 on control plots from 1997-2006 and from zero to 67 on grazed plots in those same years (Fig. 6). These differences in the number of young were significant by year but not by treatment type (Table 1). The number of young was significantly inversely correlated with RDM amounts $(r=-0.567 ; t=2.753, \mathrm{df}=16, P=0.014)$.

Yearly survival of $A$. nelsoni was low in 1997 on both treatment types ( 0.056 on controls, 0.111 on grazed plots), reached a peak in 2000 ( 0.583 controls, 0.429 grazed), and then decreased into 2004 and 2005 ( 0.121 controls, 0.200 grazed), which coincided with a steady increase in population numbers from 2000 until 2005 on both treatment types (Fig. 7). Survival differed significantly by year, but not by sex, treatment, or the interaction of year $\times$ sex $\times$ treatment (Table 1$)$. The majority of $A$. nelsoni $(77.3 \%)$ we captured were found only once, but some squirrels were caught up to 3 y after first capture (minimum age of 4 y) and we caught one male and one female 4 y after first capture on control plots (Table 3 ), making them at least $5 \mathrm{y}$ old at last capture. Longevity values based on recaptures were similar between males and females and between grazed and control plots (Table 3).

For $A$. nelsoni on grazed plots, the best models $\left(\Delta \mathrm{AIC}_{\mathrm{c}}<2\right)$ to describe survivorship and recapture rates included survivorship by time and recapture rate by group (sex) and survivorship by group and recapture rate by time (Table 4). For A. nelsoni on control plots, the best models were survivorship by group times recapture rate by time and static survivorship times recapture rate by group (Table 4). Apparent static yearly survivorship for female $(0.405)$ and male squirrels $(0.368)$ on grazed plots did not differ significantly, nor did survivorship values for females $(0.381)$ from males $(0.317)$ on control plots, nor did these values differ significantly between grazed and control plots (Table 5). Yearly recapture rates also did not differ significantly between sexes within or between plot type (Table 5). Populations of male and female squirrels on both treatment types over the 10-year study were growing $(\lambda>1.0)$ and did not differ significantly (Table 5). 
Table 1. Results of General Linear Models tests of sex ratios, adult weights, percentage of adults reproductive, number of young captured, and yearly survival of San Joaquin antelope squirrel (Ammospermophilus nelsoni) in grazed and control (ungrazed) plots based on yearly trapping from 1997-2006 at the Lokern study site in the southern San Joaquin Desert of California, USA. Output includes degrees of freedom (df), adjusted sums of squares (Adj SS), adjusted mean squares (Adj MS), $F$ value, and $P$ value. Because of lack of reproductive sign of females, only males were tested in percentage of adults reproductive.

\begin{tabular}{|c|c|c|c|c|c|}
\hline Source & df & Adj SS & Adj MS & $F$ & $P$ \\
\hline \multicolumn{6}{|l|}{ Sex Ratios } \\
\hline Year & 9 & 14748.7 & 1638.75 & 17.33 & $<0.001$ \\
\hline Sex & 1 & 0.0 & 0.03 & 0.00 & 0.987 \\
\hline Treatment & 1 & 455.6 & 455.63 & 4.82 & 0.041 \\
\hline Year $\times$ Sex $\times$ Treatment & 9 & 482.7 & 53.64 & 0.57 & 0.807 \\
\hline \multicolumn{6}{|l|}{ Weights } \\
\hline RDM & 1 & 339 & 338.9 & 2.11 & 0.147 \\
\hline Invertebrates & 1 & 22 & 21.9 & 0.14 & 0.712 \\
\hline Year & 8 & 16088 & 2010.9 & 12.52 & $<0.001$ \\
\hline Treatment & 1 & 325 & 325.4 & 2.03 & 0.155 \\
\hline Sex & 1 & 16707 & 16707.2 & 104.0 & $<0.001$ \\
\hline Year $\times$ Sex & 8 & 5963 & 745.3 & 4.64 & $<0.001$ \\
\hline Treatment $\times$ Sex & 1 & 28 & 27.8 & 0.17 & 0.678 \\
\hline Year $\times$ Treatment $\times$ Sex & 8 & 2561 & 320.1 & 1.99 & 0.045 \\
\hline \multicolumn{6}{|l|}{ Percentage Reproductive } \\
\hline Year & 9 & 0.4215 & 0.0468 & 4.27 & 0.021 \\
\hline Treatment & 1 & 0.0117 & 0.0117 & 1.06 & 0.329 \\
\hline \multicolumn{6}{|l|}{ Number of Young } \\
\hline $\mathrm{RDM}$ & 1 & 58.000 & 58.000 & 0.26 & 0.624 \\
\hline Year & 8 & 7316.3 & 914.53 & 4.14 & 0.039 \\
\hline Treatment & 1 & 492.40 & 492.38 & 2.23 & 0.179 \\
\hline \multicolumn{6}{|l|}{ Yearly Survival } \\
\hline $\mathrm{RDM}$ & 1 & 0.0209 & 0.0209 & 1.68 & 0.217 \\
\hline Invertebrates & 1 & 0.0651 & 0.0651 & 5.24 & 0.039 \\
\hline Year & 7 & 0.3509 & 0.0501 & 4.03 & 0.015 \\
\hline Sex & 1 & 0.0480 & 0.0480 & 3.86 & 0.071 \\
\hline Treatment & 1 & 0.0001 & 0.0001 & 0.00 & 0.948 \\
\hline Year $\times$ Sex $\times$ Treatment & 7 & 0.0216 & 0.0031 & 0.25 & 0.964 \\
\hline
\end{tabular}




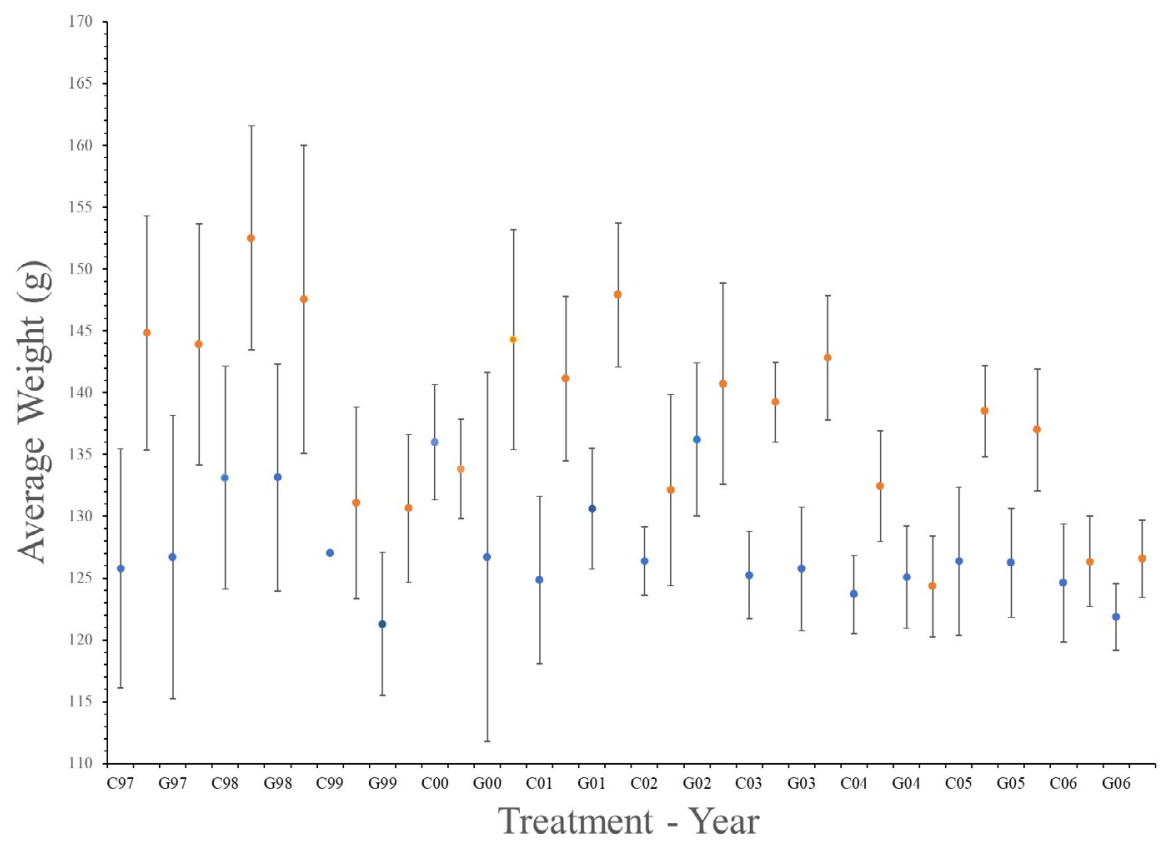

Figure 5. Weights of adult male (orange symbols) and female (blue symbols) San Joaquin antelope squirrels (Ammospermophilus nelsoni) in control (C) and grazed (G) plots from 1997-2006 at the Lokern study site in the southern San Joaquin Desert of California, USA. The symbols are the means and the vertical lines are the 95\% confidence intervals.

Table 2. The percentage of male San Joaquin antelope squirrel (Ammospermophilus nelsoni) in grazed and control (ungrazed) plots that were scrotal from 1997-2006 at the Lokern study site in the southern San Joaquin Desert of California, USA.

\begin{tabular}{ccc}
\hline Year & $\begin{array}{c}\text { Control } \\
\text { \%Scrotal }\end{array}$ & $\begin{array}{c}\text { Grazed } \\
\text { \%Scrotal }\end{array}$ \\
\hline 1997 & 18.2 & 20.0 \\
1998 & 44.4 & 66.7 \\
1999 & 33.3 & 0 \\
2000 & 14.3 & 9.10 \\
2001 & 7.10 & 16.1 \\
2002 & 0 & 0 \\
2003 & 9.4 & 3.0 \\
2004 & 20.5 & 10.4 \\
2005 & 35.0 & 13.7 \\
2006 & 0 & 1.70 \\
\hline
\end{tabular}




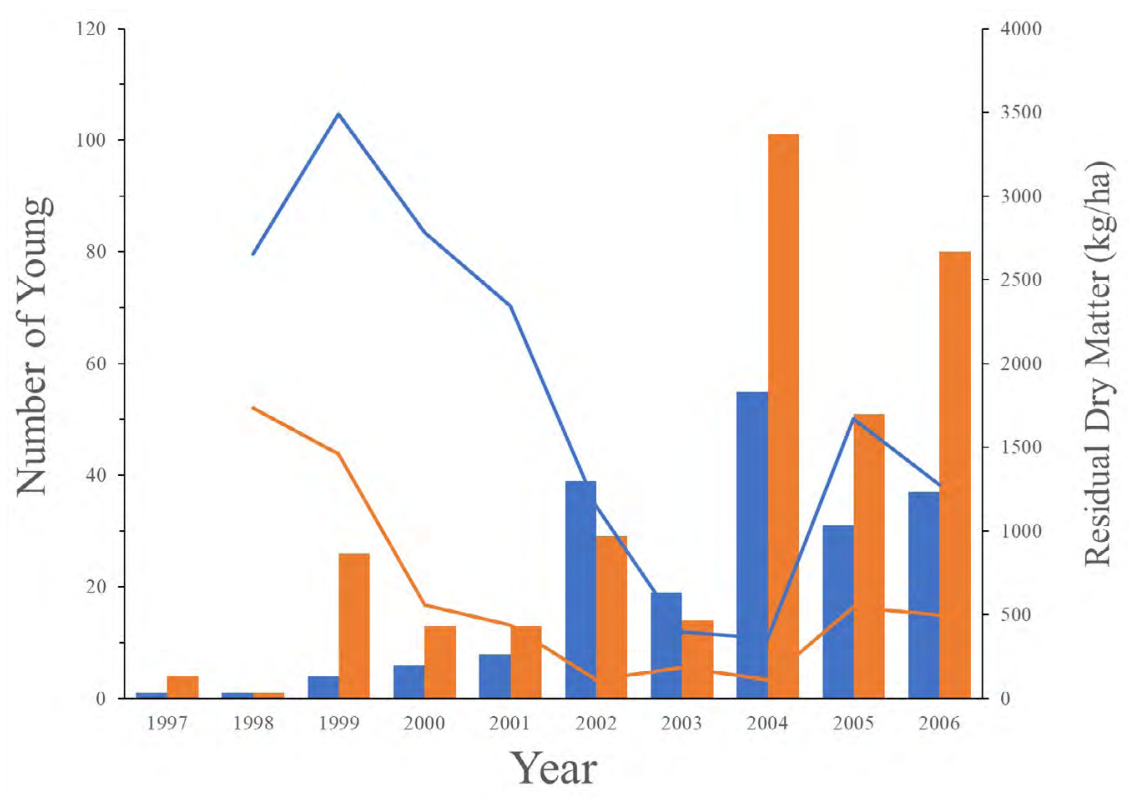

Figure 6. The number of young San Joaquin antelope squirrels (Ammospermophilus nelsoni) in control (blue bars) and grazed (orange bars) plots and residual dry matter (RDM) from 1997-2006 at the Lokern study site in the southern San Joaquin Desert of California, USA. RDM is shown as blue lines for controls and orange lines for grazed plots.

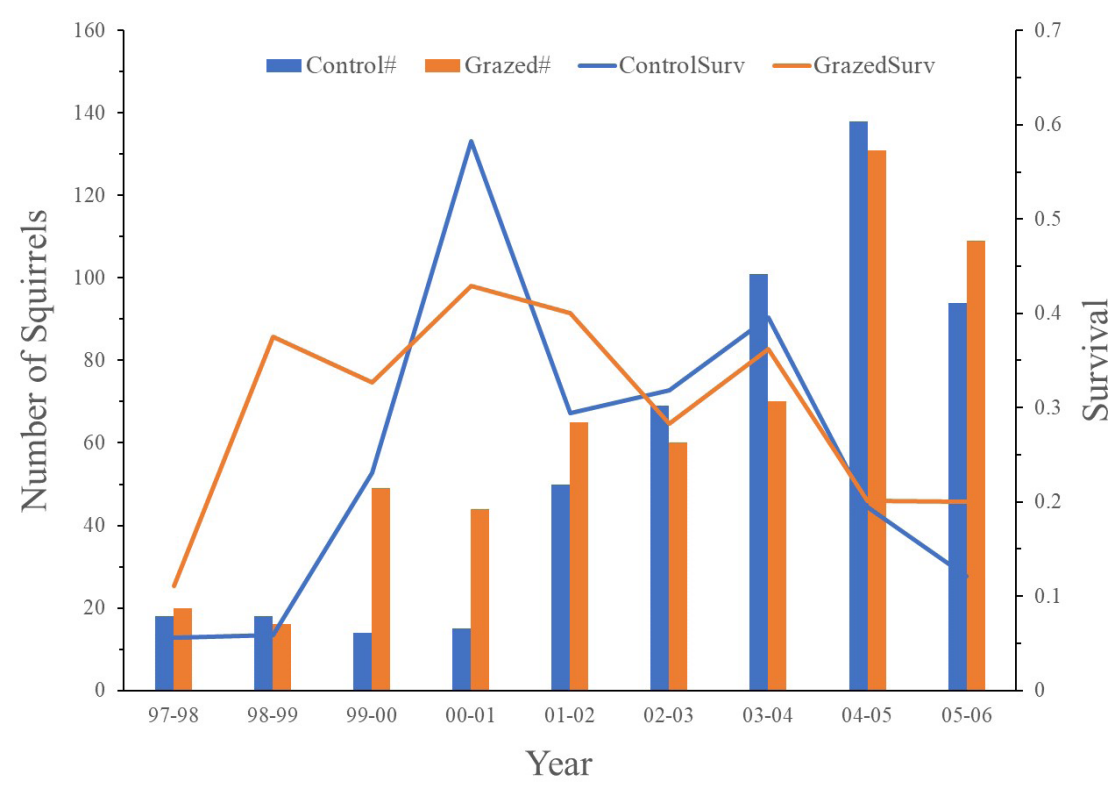

Figure 7. The number of all San Joaquin antelope squirrels (Ammospermophilus nelsoni) in control (blue bars) and grazed (orange bars) plots and yearly survival from 1997-2006 at the Lokern study site in the southern San Joaquin Desert of California, USA. Yearly survival is shown as blue lines for controls and orange lines for grazed plots. 
Table 3. Longevity (number of individuals caught and proportion of captures below) of San Joaquin antelope squirrel (Ammospermophilus nelsoni) in grazed and control (ungrazed) plots based on yearly trapping from 1997-2006 at the Lokern study site in the southern San Joaquin Desert of California, USA. Minimum age is the number of years a squirrel was found on a plot.

\begin{tabular}{llccccc}
\hline Treatment & Sex & \multicolumn{5}{c}{ Minimum age (years) } \\
& & 1 & 2 & 3 & 4 & 5 \\
\hline Control & Females & 120 & 31 & 16 & 1 & 1 \\
& Proportion & 0.710 & 0.183 & 0.095 & $<0.001$ & $<0.001$ \\
& Males & 168 & 28 & 10 & 0 & 1 \\
\multirow{5}{*}{ Grazed } & Proportion & 0.812 & 0.135 & 0.048 & 0 & $<0.001$ \\
& Females & 153 & 35 & 20 & 7 & 0 \\
& Proportion & 0.712 & 0.163 & 0.093 & 0.033 & 0 \\
& Males & 172 & 36 & 11 & 3 & 0 \\
& Proportion & 0.775 & 0.162 & 0.050 & 0.014 & 0 \\
\hline
\end{tabular}

Table 4. Cormack-Jolly-Seber model set (first 5 of 16 for each plot type) analyzing the effects of group (female, male) and time on apparent survivorship $(\Phi)$ and recapture rates $(p)$ of San Joaquin antelope squirrels (Ammospermophilus nelsoni) caught in grazed and control (ungrazed) plots from 1997 to 2006 at the Lokern study site in the San Joaquin Desert of California. Abbreviations are $\mathrm{t}=$ time,$g=$ group,$()=$. static value, $\mathrm{AIC}=$ Akaike Information Criterion, $\Delta \mathrm{AIC}_{\mathrm{c}}=$ difference between model $\mathrm{AIC}_{\mathrm{c}}$ and lowest $\mathrm{AIC}_{\mathrm{c}}$ in the model set, $\omega=$ Akaike model weight, $k=$ number of estimable parameters, and Deviance $=$ measure of model fit.

\begin{tabular}{lccccc}
\hline Model & $\mathrm{AIC}_{\mathrm{c}}$ & $\Delta \mathrm{AIC}_{\mathrm{c}}$ & $\omega$ & $k$ & Deviance \\
\hline Grazed & & & & & \\
$\Phi(\mathrm{t}) \mathrm{p}(\mathrm{g})$ & 750.7443 & 0 & 0.48578 & 11 & 79.9346 \\
$\Phi(\mathrm{g}) p(\mathrm{t})$ & 752.2334 & 1.4891 & 0.23072 & 11 & 81.4236 \\
$\Phi(\mathrm{t}) p()$. & 753.5748 & 2.8305 & 0.11798 & 10 & 84.8450 \\
$\Phi(\mathrm{g} \times \mathrm{t}) p()$. & 755.1651 & 4.4208 & 0.05327 & 19 & 67.4416 \\
$\Phi() p.(\mathrm{t})$ & 755.7443 & 5 & 0.03988 & 10 & 87.0145 \\
Control & & & & & \\
$\Phi(\mathrm{g}) p(\mathrm{t})$ & 545.6777 & 0 & 0.65998 & 11 & 59.6404 \\
$\Phi() p.(\mathrm{t})$ & 547.1749 & 1.4972 & 0.31219 & 10 & 63.2324 \\
$\Phi(\mathrm{t}) p(\mathrm{~g})$ & 553.3156 & 7.6379 & 0.01449 & 11 & 67.2784 \\
$\Phi(\mathrm{t}) p(\mathrm{t})$ & 555.1468 & 9.4691 & 0.00580 & 17 & 56.3506 \\
$\Phi(\mathrm{t}) p()$. & 555.4574 & 9.7797 & 0.00496 & 10 & 71.5149 \\
\hline
\end{tabular}




\section{DISCUSSION}

Over a 10-year study in the Lokern Natural Area in the southern part of the range of $A$. nelsoni, we found that males and females occurred in equal numbers, adult males weighed about $10 \mathrm{~g}$ on average more than adult females, and females were not in reproductive condition in the summer, although some males were. Based on live-trapping over a 10-year period (1947-1956), Hawbecker (1958) also reported that the sex ratio for A. nelsoni was even but did not provide numbers. Interestingly, sexual dimorphism with males being slightly larger than females has been reported for A. nelsoni (Best et al. 1990c) and for a congener, the white-tailed antelope squirrel (A. leucurus; Belk and Smith 1991), but not for two other congeners, Texas antelope squirrels (A. interpres; Best et al. 1990b) and Harris' antelope squirrels (A. harrisii; Best et al. 1990a). The dimorphism reported in $A$. nelsoni was based on standard external morphological measurements. Our data constitute the first quantification of sexual dimorphism in mass for A. nelsoni.

We also found evidence of a second litter being produced based on the number of young-of-the-year squirrels $(<110 \mathrm{~g})$ we found July-August on our grids, with numbers of second litter young steadily increasing over the course of the 10 years. First litters, and sometimes the only litter, are produced in March and young come above ground about the first week in April (Hawbecker 1958). Hawbecker (1958) stated that there is only one breeding season, which coincides with the one period of the year when green vegetation is present. We are quite sure that the small squirrels we found in August represent another litter. Even if some of the larger young (95-100 g) were born in March, we captured a number of young squirrels weighing $<95 \mathrm{~g}$ in August, some as small as $75 \mathrm{~g}$. By 1 June, most A. nelsoni captured on the Elkhorn Plain, southwest of our study site, weighed 95-115 g, and by late August, the lightest squirrels weighed $>100 \mathrm{~g}$ (Williams et al., unpubl. report). In southern Arizona, Neal (1965) found that for A. harrisii, at 3 mo of age it is difficult under field conditions to distinguish young-of-the-year from adult. In A. leucurus, one relatively large litter is typically produced per year (Kenagy 1981; Kenagy and Bartholomew 1985), but Bailey (1931), working in New Mexico, found what he termed half-grown young A. leucurus in late August, and he suggested that a second litter is sometimes produced. Similarly, based on embryo counts, Davis (1978) found evidence that a second litter is produced in A. interpres.

Table 5. Apparent static yearly survivorship $(\Phi)$ and recapture rate $(p)$ based on model averaging, and lambda $(\lambda)$, including upper and lower $95 \%$ confidence intervals in parentheses for female and male San Joaquin antelope squirrels (Ammospermophilus nelsoni) caught in grazed and control (ungrazed) plots from 1997 to 2006 in the San Joaquin Desert of California. Comparisons within life-history traits (down a column) did not differ significantly (based on means not intersecting confidence intervals) among any comparisons.

\begin{tabular}{lccc}
\hline Group/Sex & $\Phi$ & $p$ & $\lambda$ \\
\hline Grazed Female & $0.405(0.198,0.698)$ & $0.689(0.343,0.908)$ & $1.24(1.19,1.30)$ \\
Grazed Male & $0.368(0.171,0.668)$ & $0.579(0.255,0.851)$ & $1.24(1.19,1.30)$ \\
Control Female & $0.381(0.231,0.588)$ & $0.624(0.411,0.946)$ & $1.21(1.15,1.28)$ \\
Control Male & $0.317(0.180,0.548)$ & $0.620(0.399,0.953)$ & $1.21(1.16,1.27)$ \\
\hline
\end{tabular}


Annual survivorship over the 10 -year study varied from 0.317 to 0.405 depending on the sex and treatment plot, but there were no significant differences among survivorship estimates. Despite these relatively low rates of survivorship overall, this was high enough to estimate lambda values well over 1.0 on both grazed and control plots, indicating an increasing population for males and females on either treatment type. Based on squirrels being recaptured on a plot, we found that some squirrels can live 3-4 years (up to 5 years), although we only captured most squirrels either once or twice, which may indicate a typical life span of 1-2 years. Based on periodic live-trapping from 1947 to 1956 at a site $40 \mathrm{~km}$ west of Fresno, California, Hawbecker (1958) stated that $80 \%$ of $A$. nelsoni do not survive from one year to the next, but he found 12 individuals that lived $>1 \mathrm{y}$, and 3 that lived to almost 6 years. Using static survivorship estimates (data integrated over all 10 years of our study; Table 5), longevity can be estimated based on yearly survivorship of squirrels (above). At the low end of longevity, only $10.8 \%$ of squirrels would live to 3 years and $3.2 \%$ to 4 years. At the high end, $16.4 \%$ live to 3 years, $6.6 \%$ live to 4 years, and $2.7 \%$ live to 5 years. These estimates are not very different from longevity estimated by recaptures on plots.

We did not find any consistent treatment effect on the traits that we studied in A. nelsoni, which we think is in part due to the high variability in weather over the 10 -year study. We had high levels of RDM early in our study, grazing lowered this on treatments, and the area dried out from 2000-2004, which lowered the grass cover on the control plots despite no cattle grazing (Germano et al. 2012). High rainfall in 2005 and 2006 greatly increased herbaceous cover and grazing kept cover levels much lower on treatment plots and led to many more $A$. nelsoni on these plots (Germano et al. 2012). Although we also found many more young squirrels on grazed plots than on control plots, which added to the overall significantly higher numbers of all $A$. nelsoni on grazed plots (Germano et al. 2012), these higher numbers of young were not significantly greater than the number on control plots. Although we did not find a statistical effect of treatment on the number of young, numbers of young were negatively correlated with RDM, indicating that high levels of herbaceous cover are detrimental to this age group. Although we do not have evidence for this, it is possible that lower herbaceous cover allows both adult and young squirrels earlier detection of predators. This could lead to faster entrance into escape cover.

Our study of $A$. nelsoni population and life-history traits is only the second long-term data set for this species and compliments the pioneering work of Albert Hawbecker in the 1940s and 1950s. Like Hawbecker, we also have calculated home range sizes for male and female A. nelsoni (Germano et al. 2021). Unlike Hawbecker, though, our data are much more rigorous because we replicated our study design and therefore were able to statistically analyze trait values and trends, and our home range estimates were based on radio telemetry and not recaptures in traps. Combined, these data sets give important information about the biology of this threatened desert squirrel, which can be used to recover the species in the future.

\section{ACKNOWLEDGMENTS}

We are grateful for the funding and in-kind support provided by ARCO Oil Company, Chevron Production Company, Eureka Livestock Company, California Cattlemen's Association, California Department of Fish and Game, California Department of Water Resources, California State University (CSU) Bakersfield Foundation, Center for Natural Lands Management, Central Valley Project Conservation Program, Endangered Species 
Recovery Program (CSU Stanislaus), National Fish and Wildlife Foundation, Occidental Of Elk Hills, U.S. Bureau of Land Management, U.S. Bureau of Reclamation, U.S. Fish and Wildlife Service, and U.S. Geological Survey. We thank the many students of CSU Bakersfield who worked on the project and we also greatly appreciate the dozens of volunteers who assisted with the field work, many associated with the same agencies that contributed funding. We are especially thankful for the field assistance of Doug Barnum, Alex Brown, Kathy Sharum, and Greg Warrick. Our research was done under federal endangered species permit TE826513-2 and a Memoranda of Understanding with the California Department of Fish and Game. We are grateful to Scott Philips for making Figure 2.

\section{LITERATURE CITED}

Bailey, V. 1931. Mammals of New Mexico. North American Fauna 53:1-412.

Belk, M. C., and H. D. Smith. 1991. Ammospermophilus leucurus. Mammalian Species 368:1-8.

Best, T. L., A. S. Titus, K. Caesar, and C. L. Lewis. 1990a. Ammospermophilus harrisii. Mammalian Species 366:1-7.

Best, T. L., C. L. Lewis, K. Caesar, A. S. Titus. 1990b. Ammospermophilus interpres. Mammalian Species 365:1-6.

Best, T. L., A. S. Titus, C. L. Lewis, and K. Caesar. 1990c. Ammospermophilus nelsoni. Mammalian Species 367:1-7.

Burnham, K. P., and D. R. Anderson. 2002. Model Selection and Inference: A Practical Information-theoretic Approach. 2nd edition. Springer-Verlag, New York, NY, USA.

Cypher, B. 2001. Spatiotemporal variation in rodent abundance in the San Joaquin Valley, California. Southwestern Naturalist 46:66-75.

Cypher, B. L., C. D. Bjurlin, and J. L. Nelson. 2009. Effects of roads on endangered San Joaquin kit foxes. Journal of Wildlife Management 73:885-893.

Davis, W. B. 1978. The Mammals of Texas. Bulletin 41. Information-Education Division, Texas Parks and Wildlife Department, Austin, TX, USA.

Fiehler, C. M., B. L. Cypher, and L. R. Saslaw. 2017. Effects of oil and gas development on vertebrate community composition in the southern San Joaquin Valley, California. Global Ecology and Conservation 9:131-141.

Germano, D. J., and G. B. Rathbun. 2016. Home range and habitat use by blunt-nosed leopard lizards in the southern San Joaquin Desert of California. Journal of Herpetology 50:429-434.

Germano, D. J., G. B. Rathbun, L. R. Saslaw, B. L. Cypher, E. A. Cypher, and L. Vredenburgh. 2011. The San Joaquin Desert of California: ecologically misunderstood and overlooked. Natural Areas Journal 31:138-147.

Germano, D. J., G. B. Rathbun, and L. R. Saslaw. 2012. Effects of grazing and invasive grasses on desert vertebrates in California. Journal of Wildlife Management 76:670-682.

Germano, D. J., G. B. Rathbun, L. R. Saslaw, and B. L. Cypher. 2021. Home range and movements of San Joaquin antelope squirrels in the San Joaquin Desert of California. California Fish and Wildlife Journal, CESA Special Issue:317-328.

Grinnell, J., and J. Dixon. 1918. Natural history of the ground squirrels of California. Monthly Bulletin, California State Commission of Horticulture 7:3-116. 
Harris, J. H. 2019. Diet of the San Joaquin antelope squirrel in the southern portion of its range. Western Wildlife 6:23-28.

Hawbecker, A. C. 1947. Food and moisture requirements of the Nelson antelope ground squirrel. Journal of Mammalogy 28:115-125.

Hawbecker, A. C. 1953. Environment of the Nelson antelope ground squirrel. Journal of Mammalogy 34:324-334.

Hawbecker, A. C. 1958. Survival and home range in the Nelson antelope ground squirrel. Journal of Mammalogy 39:207-215.

Hawbecker, A. C. 1959. Parasites of Ammospermophilus nelsoni. Journal of Mammalogy 40:446-447.

Kenagy, G. J. 1981. Endogenous annual rhythm of reproductive function in the nonhibernating desert ground squirrel Ammospermophilus leucurus. Journal of Comparative Physiology 142:251-258.

Kenagy, G. J., and G. A. Bartholomew. 1985. Seasonal reproduction patterns in five coexisting California desert rodent species. Ecological Monographs 55:371-396.

Lebreton, J. D., K. P. Burnham, J. Clobert, and D. R. Anderson. 1992. Modeling survival and testing biological hypothesis using marked animals: a unified approach with case studies. Ecological Monographs 62:67-118.

Neal, B. J. 1965. Seasonal changes in body weights, fat depositions, adrenal glands, and temperatures of Citellus tereticaudus and Citellus harrisii (Rodentia). Southwestern Naturalist 10:156-166.

Otten, M. R. M., and B. L. Cypher. 1999. Occurrence and prevalence of three rodent species on the Naval Petroleum Reserves: sampling implications. Transactions of the Western Section of The Wildlife Society 35:22-28.

Pradel, R. 1996. Utilization of capture-mark-recapture for the study of recruitment and population growth rate. Biometrics 52:703-709.

Schooley, R. L., P. B. Sharpe, and B. Van Horne. 1993. Passive integrated transponders for marking free-ranging Townsend's ground squirrels. Journal of Mammalogy $74: 480-484$.

U.S. Fish and Wildlife Service (USFWS). 1998. Recovery plan for upland species of the San Joaquin Valley, California. U.S. Fish and Wildlife Service, Portland, OR, USA.

White, G. C., and K. P. Burnham. 1999. Program MARK: survival estimation from populations of marked individuals. Bird Study 46:S120-139.

Submitted 9 July 2020

Accepted 18 September 2020

Associate Editor was M. Mantor 